\title{
Effect of Processing Techniques on The Contents of Flatulence Factors and Emulsion Properties of Cowpea (Vigna unguiculata)
}

\author{
${ }^{1 *}$ ONYESOM, I; ${ }^{2+}$ ENAHOLO, AT; ${ }^{1}$ MORDI, J \\ ${ }^{a}$ Department of Medical Biochemistry, Faculty of Basic Medical Sciences, Delta State University, P.O. Box 144, Abraka, Nigeria. E-mail: \\ onyesominno@yahoo.co.uk, Tel: +234 8030528016 \\ ${ }^{\mathrm{b}}$ Department of Biochemistry, Ambrose Ali University, Ekpoma, Nigeria.
}

\begin{abstract}
The effect of some processing techniques (germination boiling and dehulling) on the soluble sugar contents and the emulsion property of processed flour were studied. Results show that germination significantly reduced the raffinose level from the third to the fifth day sprouting period $(\mathrm{P}<0.05)$. Boiling and dehulling also reduced the content of this flatus oligosaccharide (raffinose) but not to a significant proportion $(\mathrm{P}>0.05)$. The contents of other soluble sugars-galactose, glucose and sucrose were increased by germination $(\mathrm{P}<0.05)$ and boiling $(\mathrm{P}>0.05)$ but reduced by dehulling ( $>0.05)$. Germination, dehulling and boiling lowered the emulsion stability property of cowpea flour. Even though, it is not conventional to either malt or dehull cowpea seeds before cooking, individuals should be advised to do so, in order to minimize the flatus potential and the accompanied discomfort associated with beans consumption. However, such processing techniques would not be appropriate for foods that need good emulsion. @JASEM.
\end{abstract}

Cowpea, Vigna unguiculata belongs to the group of crops known as legumes which are edible seeds. Cowpea or beans as it is popularly known is indigenous to West Africa (Onigbinde and Onobun, 1993) and it is a major source of human and animal food. The vegetative part of the cowpea plant can be buried into the soil to improve its fertility, and also, cowpea is a well known leguminous cover crop. In Nigeria it is usually interplanted with cereals as a mixed crop (Oyenuga, 1968). However, legumes are especially well known to produce flatulence in humans (Onigbinde and Akinyele, 1983) due to the oligosaccharide content which form a major reserve of soluble carbohydrates during seed dormancy. In man, the enzymes $\alpha$-galactosidase is not present in the digestive system, and as such man is unable to digest oligosaccharides. However, microflora in the lower intestine previously identified as gram-positive, spore forming anaerobic bacteria of Clostridia group are able to synthesize enzymes that ferment these undigestible oligosaccharides to produce $\mathrm{CO}_{2}, \mathrm{H}_{2}$, $\mathrm{CH}_{4}, \mathrm{H}_{2} \mathrm{~S}$ and $\mathrm{NH}_{3}$ (Singh et al., 1993) The mixture of these gases produces flatulence, a discomfort that is specifically associated with consumption of low molecular weight oligosaccharides mostly present in legumes (Phillips, 1993). Raffinose, stachyose and verbascose have been identified as flatulence inducers and when digested cause accumulation of gas, discomfort, diarrhea, pain and cramps (Deshpande and Deshpande, 1991; Liew and Buckle, 1990; Phillips, 1993); a factor which has tended to render legumes less acceptable.

Nutritionists are therefore posed with the challenges of innovating processing techniques that could be used to either significantly reduce or completely eliminate the flatulence factors in foods without necessarily reducing its nutritive quality. This study thus, attempts to establish the influence of germination, boiling and dehulling on the soluble sugar (galactose, glucose, sucrose and rafinose) composition of a local cultivar of Vigna unguiculata. The potential food uses of the processed mill would also be analyzed using the emulsion stability index as this is what largely determines its acceptability and application as an ingredient in food systems.

\section{MATERIALS AND METHODS}

Seed Purchase: The seeds of a local black eyed variety of cowpea, Vigna unguiculata were purchased from a peasant farmer in Ekpoma, Edo State, Nigeria.

Seed Selection and Treatment: Mature and viable seeds with uniform size were selected by hand picking. Selected seeds were soaked in a $2 \%$ sodium hypochlorite solution for $30 \mathrm{~min}$ and washed thoroughly with distilled water several times in order to prevent microbial contamination during handling and processing.

\section{Seed Processing Techniques}

Germination: The selected and treated seeds (about 35) were placed on a moist tissue paper in a petridish for germination over a period of $1,2,3,4$, and 5 days in a dark cupboard. After each day of germination, the cowpea seeds in a particular petridish were harvested and placed in a dryer (Gallen Kamp Size 2) for $18-24 \mathrm{~h}$ at a temperature regulated between 55 and $60^{\circ} \mathrm{C}$, until a constant weight of the seeds was obtained.

Boiling: Some of the hand-picked, treated seeds were boiled at $100^{\circ} \mathrm{C}$ for $2 \mathrm{hrs}$. This treatment softened the seeds, which were then dried (as above) until a constant weight was obtained.

Dehulling: Some of the selected and treated seeds were dehulled by carefully removing the outer coat or testa of the seeds. The dehulled seeds were then 
dried to a constant weight. The raw and intact seeds were also dried to a constant weight.

Milling of Dried Seeds: The different processed (germinated, boiled, dehulled and raw intact) dried seeds were then milled separately in a hammer mill (Glen Crestonto 14-580s) to obtain a fine powder, which was stored in labeled sample bottle at room temperature.

Soluble Sugar Determination (Onigbinde and Akinyele, 1983):

Extraction of Soluble Sugars From the Milled Sample: Two grams of the milled sample was extracted for $30 \mathrm{~min}$ with $10 \mathrm{ml}$ of $80 \%$ ethanol at $60^{\circ} \mathrm{C}$ using a magnetic stirrer. The extract was filtered through a No. 1 Whatman filter paper and the ethanol evaporated in a water bath (Gallen Kamp KQ606; Citenco Ltd.) at a temperature of $80^{\circ} \mathrm{C}$ to give a final volume of $2 \mathrm{ml}$. One gram of each standard (reference) sugar (raffinose, sucrose, glucose and galactose) was dissolved in $100 \mathrm{ml}$ of distilled water to make a $1 \%$ solution.

Separation and Identification of Sugars: The soluble sugars: glucose, galactose, sucrose and raffinose in the $2 \mathrm{ml}$ extract were separated and identified using paper chromatography. Whatman No. $1(5 \mathrm{~cm} \mathrm{x}$ $45 \mathrm{~cm}$ ) was used and samples and the reference sugars were spotted with a micro-capillary tube to deliver $0.01 \mathrm{ml}$ at $2.5 \mathrm{~cm}$ from either side and $9 \mathrm{~cm}$ from the upper end of the paper. The spotted paper was eluted for $20 \mathrm{~h}$ in a chromatographic tank saturated with the vapour of a solvent mixture of nbutanol: ethanol: ammonia: water in the ratio 8:1:1:2 (v/v) (Onigbinde and Akinyele, 1983). Separation was by downward elution. Spotting and elution was duplicated. The paper was air dried after elution and one of the duplicate paper spotted was dipped into $10 \%$ silver trioxonitrate $(\mathrm{v})\left(\mathrm{AgNO}_{3}\right)$ in acetone and finally in $0.5 \mathrm{M}$ ethanolic sodium hydroxide $(\mathrm{NaOH})$ to develop the spots. The papers were dried in the oven at $80^{\circ} \mathrm{C}$ for $15 \mathrm{~min}$ and the spots were identified based on glucose retention factor, RG.

Quantitative Analysis: The identified spots (for glucose, galactose, sucrose and raffinose) were cut out carefully and each was separately soaked in $2 \mathrm{ml}$ of distilled water to ensure total dissolution of the constituent sugar in water. Then, $0.1 \mathrm{ml}$ of $5 \%$ phenol was added to each dissolved sugar followed by rapid addition of $0.5 \mathrm{ml}$ concentrated tetraoxosulphate (vi) acid $\left(\mathrm{H}_{2} \mathrm{SO}_{4}\right)$. Each tube containing the sugar-reagent mixture was then placed in a water bath to cool for 20min. The absorbance of the cooled mixture was read at 490nm using the spectrophophotometer (Spectronic 21), and the corresponding concentration was extrapolated from the standard calibration curve prepared from each reference sugar.

Flatulence Factor: The flatulence factor was determined by the proportion of raffinose, a flatus oligosaccharide that bears direct relationship to flatulence potential. Hence, its concentration is directly proportional to the flatus volume of Vigna unguiculata (Mnembuka and Eggum, 1995).

Determination of Emulsion and Foam Stability: Emulsion Stability (Okezie and Kosikowski, 1981): Half gram of each milled sample was dispersed in $12.5 \mathrm{ml}$ distilled water, then $12.5 \mathrm{ml}$ vegetable oil was added at a rate of $12.5 \mathrm{ml} / 130$ sec while blending. Each sample was blended in a warring micro-blender (Moulinex Type 276) at high speed for an additional $60 \mathrm{sec}$ and transferred into a $50 \mathrm{ml}$ graduated cylinder. Volumetric changes in the foam, oil and aqueous layers were recorded after 0.5, 2.0 and $6.0 \mathrm{~h}$.

Foam Stability: Half gram of each milled sample was blended with $40 \mathrm{ml}$ of distilled water at high speed in a warring micro-blender for $1 \mathrm{~min}$. After blending, each sample was transferred into a $100 \mathrm{ml}$ graduated cylinder. The volume of the foam in the standing cylinder after whipping was recorded as foam stability at 1,10,30,60 and 90min.

\section{RESULTS}

The results of the analysis are presented in Figures 1 - 7. The data in Fig.1 shows the mean changes in soluble sugar contents induced by seed germination (1 -5 days). 


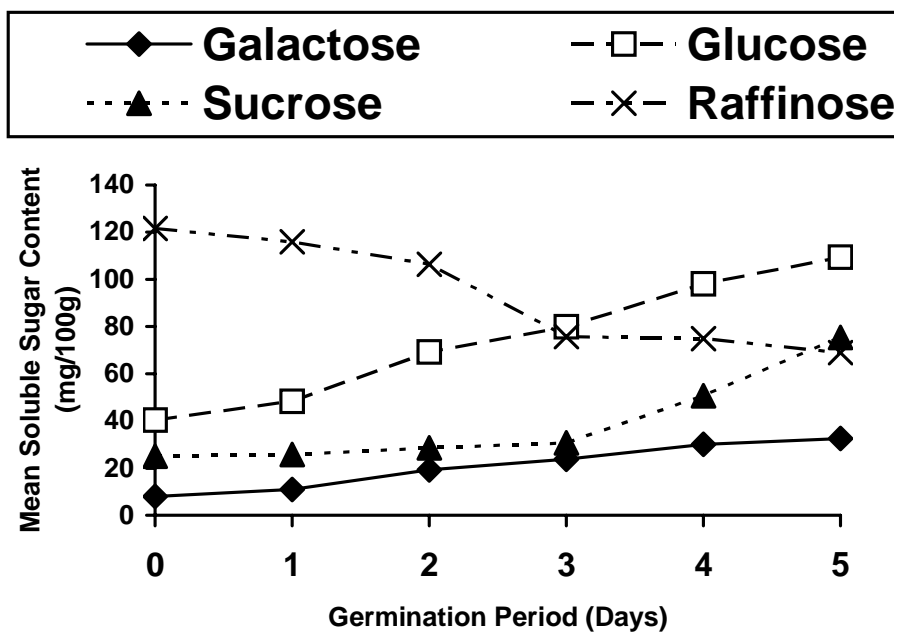

Fig 1: Soluble sugar composition of germinated, milled cowpea samples.

The concentration of galactose, glucose and sucrose increased progressively as germination proceeds but the raffinose level decreased steadily with increasing duration of germination. Except for sucrose, these changes were observed to be statistically significant from the $3^{\text {rd }}$ day of germination $(\mathrm{P}<0.05)$ using ANOVA.

Fig. 2 shows the soluble sugar changes induced by boiling and dehulling of cowpea seeds.

$\square$ Raw $\square$ Boiled $\square$ Dehulled

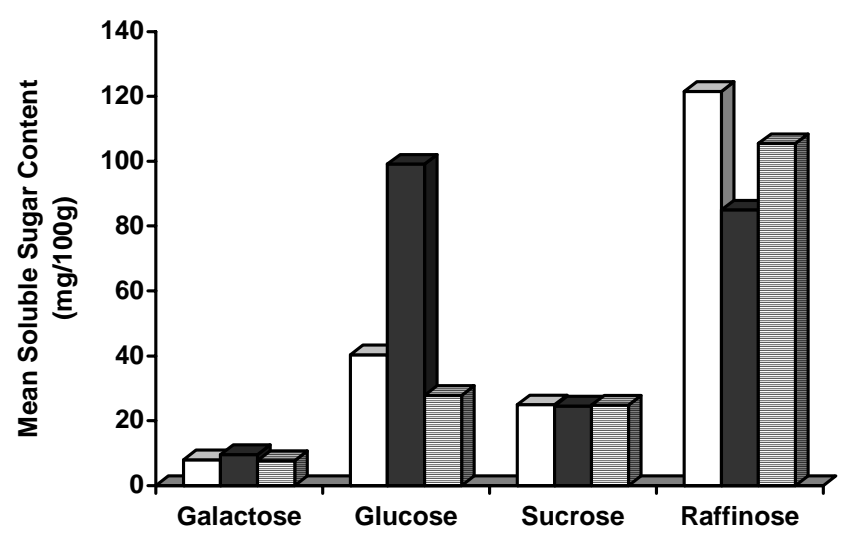

Fig. 2: Soluble sugar composition of raw, boiled and dehulled cowpea milled samples.

Boiling increased the concentrations of galactose $(\mathrm{P}>0.05)$ and glucose $(\mathrm{P}<0.05)$ but reduced the levels of sucrose $(\mathrm{P}>0.05)$ and raffinose $(\mathrm{P}<0.05)$. Dehulling insignificantly $(\mathrm{P}>0.05)$ decreased the concentrations of all the soluble sugars determined. Fig. 3 shows the emulsion stability after $0.5 \mathrm{~h}$ (Fig. 3a), 2.0h (Fig. 3b) and $6.0 \mathrm{~h}$ (Fig. 3c) of the foam, oil and aqueous phase of the cowpea milled samples. 


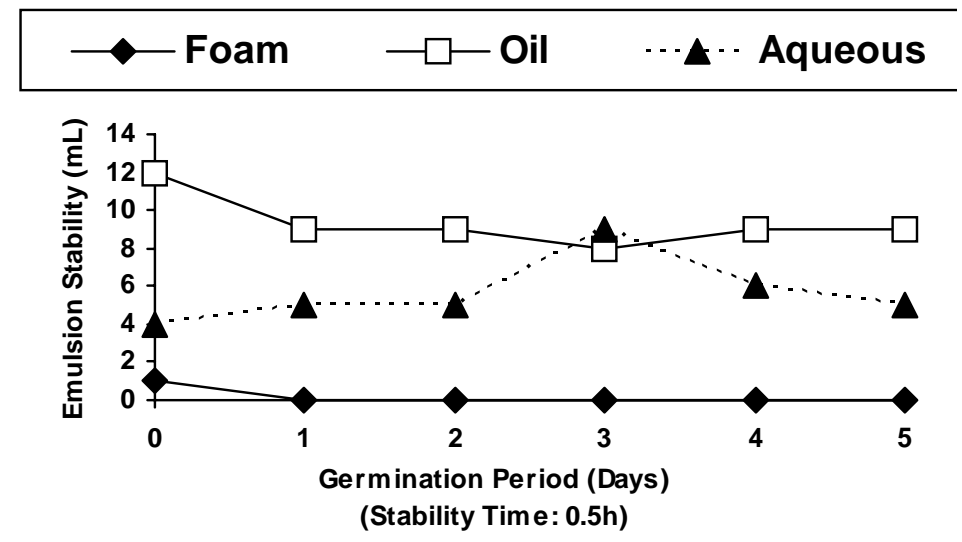

Fig 3a: Emulsion Stability of germinated Cowpea milled sample after 0.5h
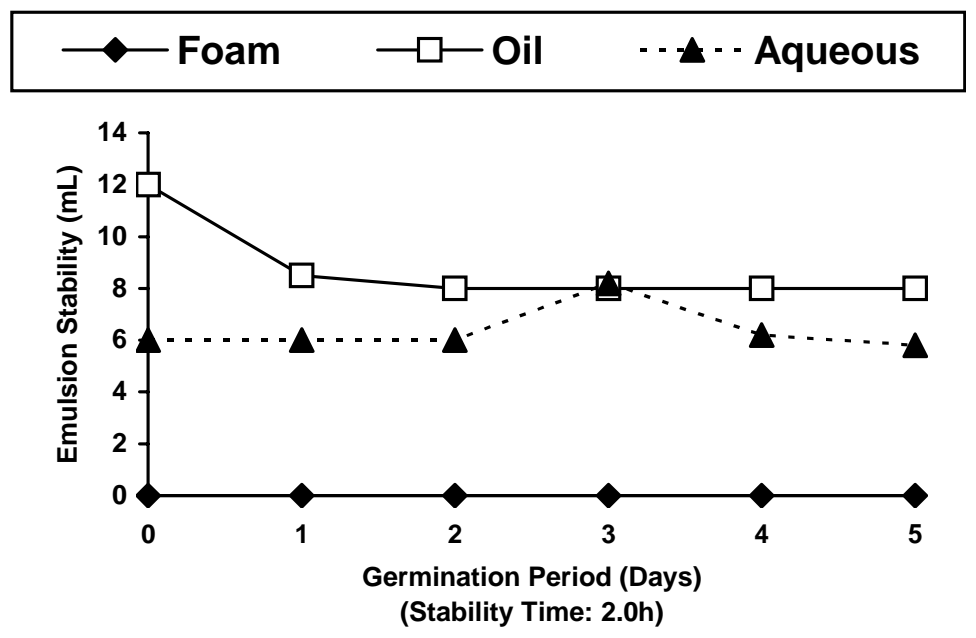

Fig 3b: Emulsion Stability of germinated Cowpea milled sample after 2.0h

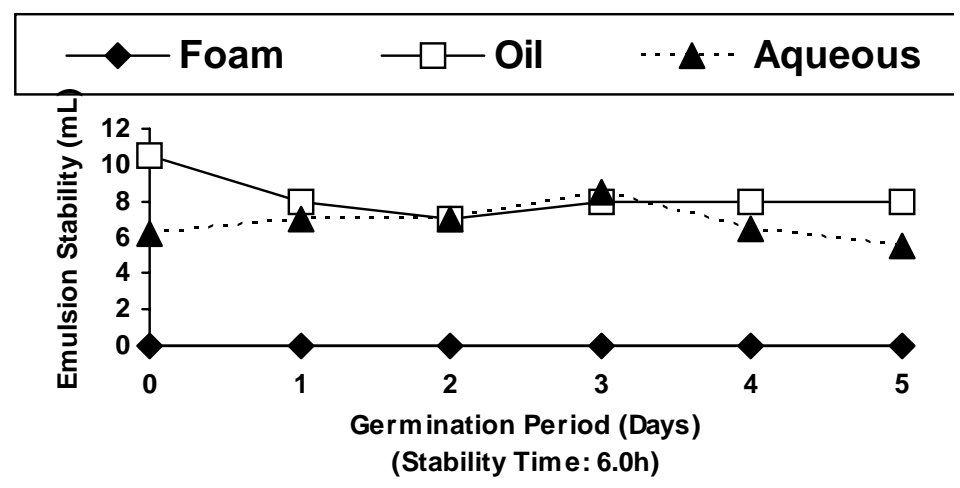

Fig 3c: Emulsion Stability of germinated Cowpea milled sample after 6.0h

Fig. 3c, shows that after $6 \mathrm{~h}$ of stability, the foam layer disappeared completely, oil layer decreased from $10.5 \mathrm{ml}$ (raw) to $7.0 \mathrm{ml}$ (day 2), but increased to $8.0 \mathrm{ml}$ (in day 5). The aqueous layer also increase from $6.2 \mathrm{ml}$ (raw) to $8.5 \mathrm{ml}$ (in day 3 ) but the day 5 sample decreased to $5.8 \mathrm{ml}$. 


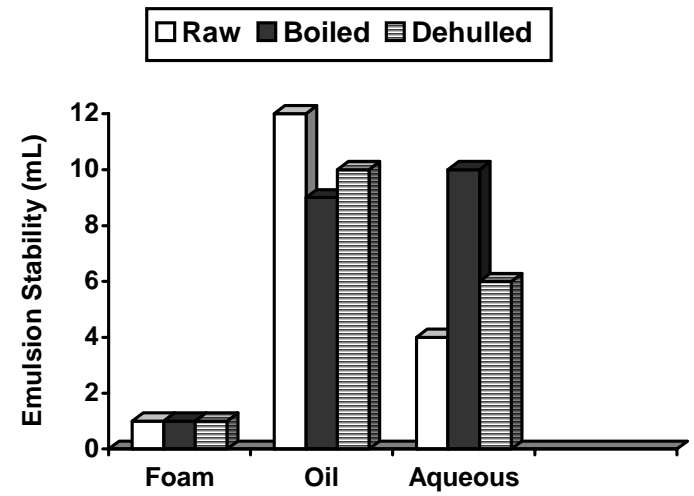

Fig 4a: Emulsion Stability of raw, boiled and dehulled Cowpea milled sample after $0.5 \mathrm{~h}$

$\square$ Raw $\square$ Boiled 目Dehulled

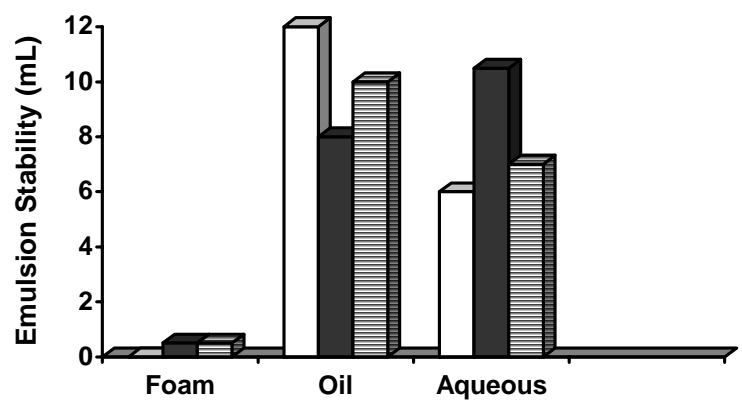

Fig 4b: Emulsion Stability of raw, boiled and dehulled Cowpea milled sample after 2.0h

$\square$ Raw $\square$ Boiled 目 Dehulled

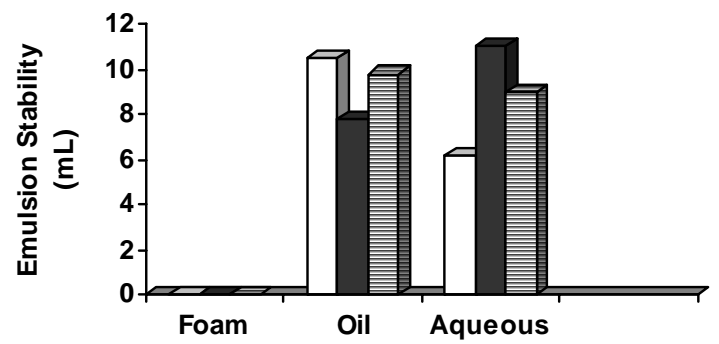

Fig 4c: Emulsion Stability of raw, boiled and dehulled Cowpea milled sample after 6.0h

Fig. 4 (a,b \& c), show the emulsion stability of boiled and dehulled cowpea milled sample after 0.5h (Fig. 4a), 2.0h (Fig. 4b) and 6.0h (Fig. 4c) of the foam, oil and aqueous phase. Boiling and dehulling produced similar effects on emulsion stability when compared with the germinated sample using the raw sample as reference. In addition, it was observed that after $6 \mathrm{~h}$ of stability the raw, $4^{\text {th }}$ and $5^{\text {th }}$ day germinated samples did not separate out completely, indicating a more stable 
emulsion. Fig. 5 shows foam stability of raw (day

$0)$

and
(1-5 days) cowpea milled sample after 1min, 10min, 60min and 90min after whip.

\section{Fig 5: Foam Stability of germinated Cowpea milled sample. Missing figure. Please supply}

The data presented on Fig. 5, indicates that after $90 \mathrm{~min}$ of stability, the foam stability increased from $2.0 \mathrm{ml}$ (raw) to $3.5 \mathrm{ml}$ (in day 5), while the first and second day germinated samples had stable foam, 30 and 60min respectively after whip. The third, fourth and fifth day germinated samples had a stable foam at 10 and 60 min respectively. Fig. 6, shows the foam stability of boiled and dehulled cowpea milled samples after $1 \mathrm{~min}, 10 \mathrm{~min}, 30 \mathrm{~min}, 60 \mathrm{~min}$ and $90 \mathrm{~min}$ of whip.

\section{$\square$ Raw $\square$ Boiled 目Dehulled}

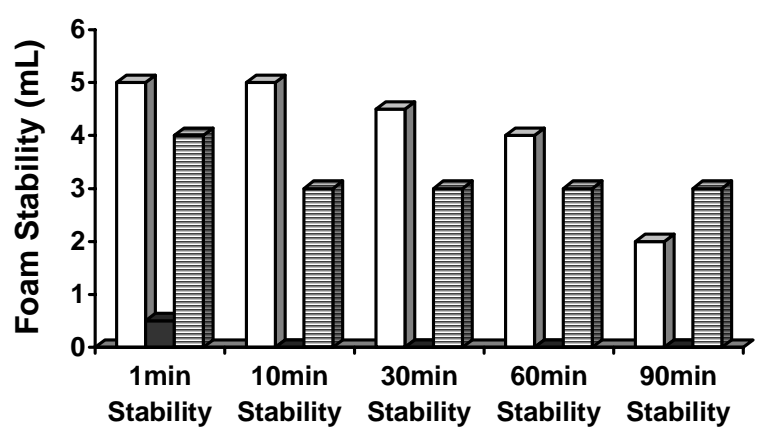

Fig. 6: Foam stability of raw, boiled and dehulled cowpea milled samples.

For dehulled sample, foam stability was $4.0 \mathrm{ml}$ after a minute stability and $3.0 \mathrm{ml}$ after 90 min stability, but for the boiled sample, foam completely disappeared after $10 \mathrm{~min}$ of stability.

\section{DISCUSSION}

Galactose, glucose and sucrose contents progressively increased and were found to have a respective percentage increase of about 307\%, 200\% and 202\% at the end of the 5-day germination period, but raffinose, an oligosaccharide steadily decreased by $67 \%$ at the end of the same germination period. (Fig. 1) A similar decrease in raffinose with subsequent increase in sucrose and glucose has been reported (Abudu and Akinyele, 1989). Liew and Buckle (1990) found that germination rapidly decreased the stachyose and raffinose contents in pigeonpea cotyledon by $3^{\text {rd }}$ day, while the total soluble carbohydrates predominantly sucrose increased steadily during the first five days but reduced thereafter. The decrease in raffinose as days of germination increased can be attributed to the presence of the enzyme, $\alpha$ - galactosidase which hydrolyzes raffinose to the respective monosaccharides. The increase in galactose suggests that raffinose (and perhaps, other oligosaccharides) might have been degraded since almost all oligosaccharides contain at least one galactose unit. However, the increase in sucrose (and glucose) may be attributed to the degradation of starch and other related polysaccharides by the $\alpha$ - and $\beta$-amylase and debranching enzyme, $\alpha 1 \rightarrow 6$ glucosidase. While boiling was found to increase the concentration of galactose and glucose, it was however discovered to reduce the concentration of sucrose and raffinose. Galactose and glucose were found to increase by $19.4 \%$ and $146 \%$ respectively, but sucrose and raffinose decreased by $1.8 \%$ and $30 \%$ after boiling. The increase in concentrations of galactose and glucose coupled with subsequent decrease in the levels of sucrose and raffinose shows that the two latter molecules are heat labile. 
Dehulling of cowpea reduced the levels of all the soluble sugars (Fig.2). Galactose, glucose, sucrose and raffinose decreased by $3.13 \%, 31.10 \%, 0.40 \%$ and $13.20 \%$ respectively, in the dehulled sample. This observation, suggests a possible localization of all the soluble sugars in the seed coat.

Although, this study does not report the total amount of oligosaccharides present in the cowpea, Vigna unguiculata, it is of biochemical interest vis-à-vis cowpea beans digestion, which germination could lead to a reduction in the level of raffinose (and possibly other oligosaccharides) in beans. Mnembuka and Eggum (1995) observed that a $5 \mathrm{~g}$ portion of raffinose caused an elevation in flatus volume in man, equivalent to that produced by $100 \mathrm{~g}$ cowpeas, on the average, which represents an elevation of about $300 \mathrm{ml}$ in flatus volume. A mean value of $121.5 \mathrm{mg}$ raffinose/100g raw sample reported in this study therefore, indicates that the consumption of an average meal of cowpea beans could cause some discomfort in man, but germination significantly reduced the raffinose level, a flatus oligosaccharide. Nevertheless, there are other oligosaccharidesstachyose, melibiose and verbascose with potential flatulence property which may or may not be altered by germination. Raw, $4^{\text {th }}$ and $5^{\text {th }}$ day germinated samples had high emulsion stability (Fig.3). This is because their emulsions did not separate completely. Sathe, et al. (1982) reported that it is the globular nature of food materials that confers a high emulsion stability. The knowledge of emulsion stability helps in ice cream, baking and high protein food production in food industries. Again, the $5^{\text {th }}$ day germinated sample had stable foam, 60min after whip. Paredes Lopez et al., (1991) reported that foam stability is important because whipping agents depend on its ability to maintain the whip as long as possible. The processing techniques used increased the soluble sugar contents except that of raffinose, and reduced the emulsion and foam stability of the processed flours. Although, not a common tradition, consumers should be encouraged to either germinate or dehull bean seeds before cooking in order to reduce the level of the flatus potential and its associated discomfort. However, such treatment would not be suitable for foods that require good emulsion and foaming properties.
Acknowledgement: We sincerely acknowledge the immense contribution of Prof. A.O. Onigbinde, Prof. L.A.D. Duru and the Laboratory Staff members of P.T.I. and SPDC - West, Warri.

\section{REFERENCES}

Abudu, IA; Akinyele, OI (1989) Effect of germination on the oligosaccharides, trypsin inhibitors and nutrient content of cowpea milk. Food Chem 35: 161-165.

Deshpande, US; Deshpande, SS (1991) Legumes. In: DK Salunke \& SS Deshpande, Foods of Plant Origin: Production, Technology, and Human Nutrition. Van Nostrand and Reinhold, New York, pp 137-300.

Liew, CCV; Buckle, KA (1990) Oligosaccharide levels in pigeonpea and pigeonpea tempe. ASEAN Food J 5:79-81.

Mnembuka, BV; Eggum, BO (1995) Comparative nutritive value of winged bean (Psophocarpus tetragonolobus (L) DC) and other legumes grown in Tanzania. Plant Foods Hum Nutri 47:333-338.

Okezie, BO; Kosikowski, FV (1981) Extractability and functionality of protein from yeast cells grown on cassava hydrolysate. Food Chem 6:711.

Onigbinde, AO; Akinyele, IO (1983) Oligosaccharide contents of twenty varieties of cowpea in Nigeria. J Food Sci 48:1252-1258.

Onigbinde, AO; Onobun, V (1993) Effects of $\mathrm{pH}$ on some cooking properties of cowpea $(V$. unguiculata). Food Chem 47:125-127.

Oyenuga, VA (1968) Nigeria's Food and Feeding Stuffs: Their Chemical and Nutritional Values. $3^{\text {rd }}$ ed., Caxton Press (WA) Ltd, Ibadan.

Paredes - Lopez, O; Ordorica-Falomir, C; Olivares, MR (1991) Chickpea protein isolates: physicochemical, functional and nutritional characteristics. J Food Sci 56: 726-729. 
Phillips, RD (1993) Starchy legumes in human nutrition, health and culture. Plant Foods Hum Nutri 44:195-211.

Sathe, SK; Deshpande, SS; Salunke, DK (1982) Functional properties of winged beans (Psophocarpus tetragonolobus L) proteins. J Food Sci 47:504-510.

Singh, U; Rao, PN; Subrahmanyam, N; Saxena, K (1993) Cooking characteristics, chemical composition and protein quality of newly developed genotypes of pigeonpea (Cajanus cajan L). J Sci Food Agric 61:395-400. 